Article

\title{
Combined Economic and Mechanical Performance Optimization of Recycled Aggregate Concrete with High Volume of Fly Ash
}

\author{
Rawaz Kurda ${ }^{(\mathbb{D}}$, Jorge de Brito * and José D. Silvestre ${ }^{\mathbb{1}}$ \\ Civil Engineering Research and Innovation for Sustainability (CERIS), Civil Engineering, Architecture and \\ Georresources Department, Instituto Superior Técnico, Universidade de Lisboa, Av. Rovisco Pais, \\ 1049-001 Lisbon, Portugal; rawaz.saleem@gmail.com (R.K.); jose.silvestre@ist.utl.pt (J.D.S.) \\ * Correspondence: jb@civil.ist.utl.pt
}

Received: 29 June 2018; Accepted: 18 July 2018; Published: 20 July 2018

Featured Application: This study provides a tool to help the construction sector to choose the most cost-efficient concrete mixes made with alternative sustainable materials, according to the target application.

\begin{abstract}
This study intends to evaluate high and low-strength concrete mixes made with high volume of fly ash (FA) and recycled concrete aggregates (RCA) from both a mechanical and economic point of view. For this purpose, the mechanical characteristics of concrete, namely compressive strength $\left(f_{\mathrm{cm}}\right)$, splitting tensile strength $\left(f_{\mathrm{ctm}}\right)$, and modulus of elasticity $\left(\mathrm{E}_{\mathrm{cm}}\right)$ were correlated with the cost of $1 \mathrm{~m}^{3}$ of concrete mixes, taking into account the most common scenarios (e.g., cost of the raw materials, transportation between supplier and concrete plant, and mixing procedure) in the centre of Portugal. The results show that the incorporation of FA and RCA are detrimental to the mechanical properties of concrete. $\mathrm{E}_{\mathrm{cm}}$ is predominantly influenced by RCA, and " $\mathrm{fm}_{\mathrm{cm}}$ " and " $f_{\mathrm{ctm}}$ " are mainly controlled by FA incorporation. However, after a given age, the rate of the strength development $\left(f_{\mathrm{cm}}, f_{\mathrm{ctm}}\right.$ and $\left.\mathrm{E}_{\mathrm{cm}}\right)$ of RCA concrete containing FA significantly accelerates over time relative to the reference concrete (without FA and RCA) and to the mixes made with either RCA or FA. Furthermore, the cost of concrete does not significantly change by incorporating RCA. The use of superplasticizer (SP) significantly increases the cost of concrete. However, the higher cost of concrete due to the use of SP can be offset by replacing cement with FA. Regarding the optimization process, concrete mixes with the lowest cost may not necessarily be the optimum choice regarding cost efficiency. In fact, the mechanical properties of concrete also need to be considered to aid the decision on the optimal concrete mix. Finally, the results show that the optimum mixes in terms of cost and mechanical characteristics are mostly the ones made with simultaneous incorporation of RCA, FA, and SP, rather than with their individual incorporation.
\end{abstract}

Keywords: concrete; compressive strength; splitting tensile strength; modulus of elasticity; economy; optimization; fly ash; recycled concrete aggregates

\section{Introduction}

Concrete can be considered as the most demanded product in the construction industry. Provided a given durability is guaranteed, the cost and strength characteristics of concrete are essential in the choice of the mix. Generally, for the same strength class, apart from taxes, the cost of concrete depends on the economy of the country, namely the cost of labour of transportation, and the type and availability of the materials (Figure 1). Therefore, it may not be reliable to classify concrete based on a 
specific price value for all countries. In this study, the most common scenario for the centre of Portugal is considered to assess the cost of concrete mixes.

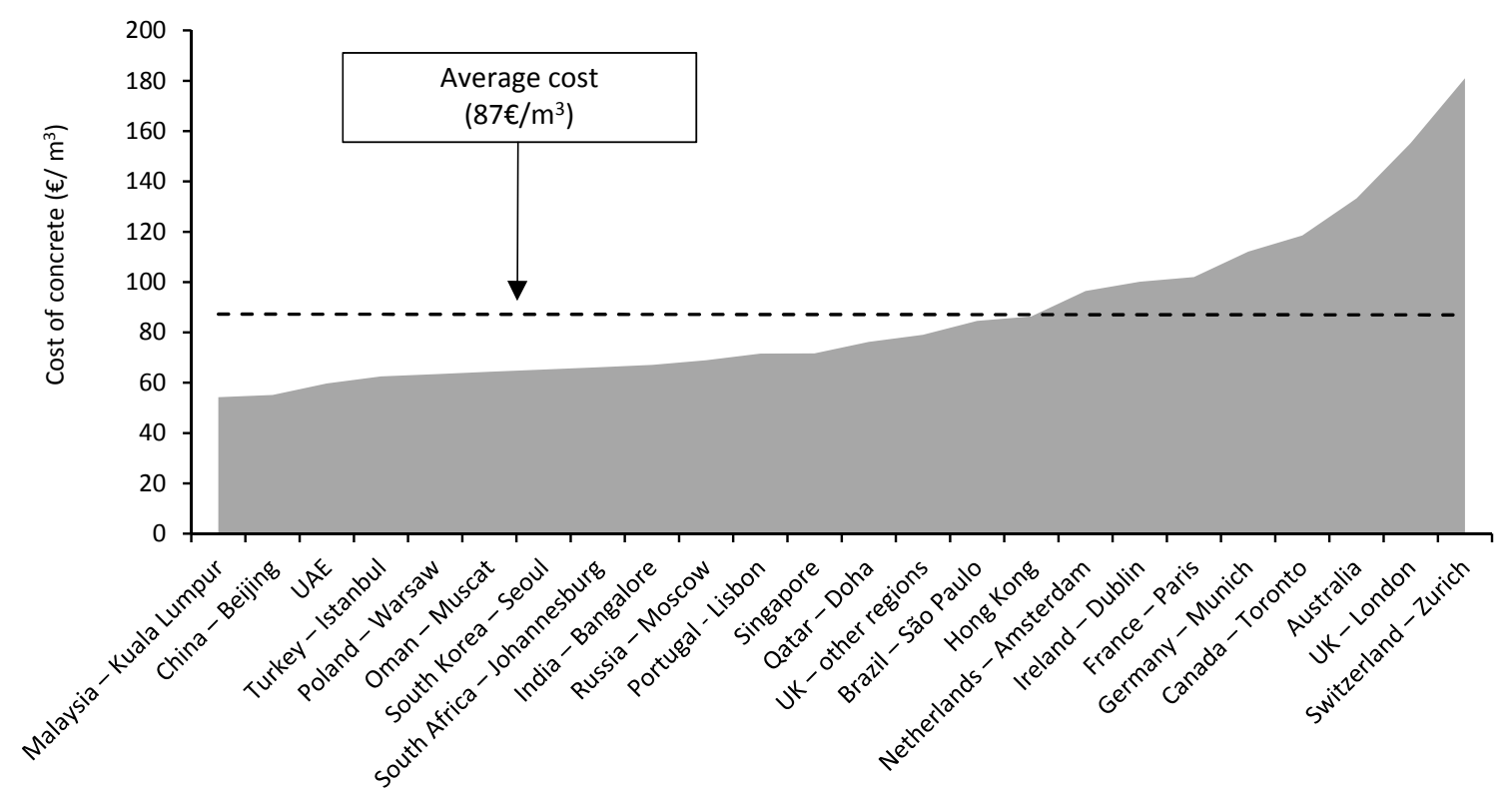

Figure 1. Cost of concrete (C30/37) in different countries excluding taxes (adapted from an international construction market survey in 2016 [1]).

Furthermore, the ranking of the best concrete mixes in terms of economy does not necessarily select the one with the lowest cost. In fact, the strength of concrete is also another important factor to aid the selection of the optimal concrete mix. For example, lower-strength concrete mixes require a higher cross-section of the structural elements, relative to higher strength concrete, and that directly affects the total amount of concrete consumed to build the structure and the total cost as a result. In fact, a study by Silva et al. [2] for recycled concrete aggregates (RCA) concrete concluded that, for a simply supported beam (rectangular cross-section), the strength of concrete affects the cross-section of the beam (Equation (1)). Similar facts can be true for cost and durability of the concrete mixes in which the thickness of the concrete cover is affected by its durability characteristics [3].

$$
M_{R d}=0.8095 \cdot b \cdot x \cdot f_{c k} \cdot \gamma_{c} \cdot z
$$

where $M_{R d}$ is cross-section's design resisting moment, $b$ is the cross-section's width (m), $x$ is the concrete compression zone's height $(\mathrm{m}), f_{c k}$ is the characteristic compressive strength $(\mathrm{MPa}), \gamma_{c}$ is the concrete's partial safety factor for ultimate limit state (equal to 1.50), and $z$ is the distance between the pressure centre of the concrete compression zone and the centre of the bottom steel reinforcement $(\mathrm{m})$, which is equal to Equation (2). The value of $x$ was solved by considering $M_{R d}$ equal to the beam's mid-span design bending moment.

$$
z=d-0.416 \cdot x
$$

where depth $(d)$ is the distance between the rectangular cross-section's top and the centre of the bottom steel reinforcement.

To date, the characteristics of concrete containing high volume of fly ash (FA) [4-7], recycled concrete aggregate (RCA) [8-15], and both FA and RCA [16-20] have been studied in terms of quality. Also, the life cycle assessment [20-24], toxicity [25], and economy [26,27] of concrete mixes made with both FA and RCA have been investigated. However, the knowledge related to the combined effects of high volumes of FA and RCA from a mechanical and economic point view is still very scarce. Thus, this study focuses on optimizing concrete containing RCA and FA with and without superplasticizer 
(SP) in terms of the mechanical and cost characteristics to find whether there are advantages in terms of cost efficiency of using the mentioned non-conventional materials instead of traditional ones.

\section{Materials and Methods}

\subsection{Mechanical Strength}

In terms of materials and concrete mix design, Ordinary Portland cement-OPC (CEM I 42.5 $\mathrm{R})$ and FA (type F) were used as binders. The geological nature of the fine (size fraction (di/Di) of $0 / 4 \mathrm{~mm}$ ) and coarse (di/Di of $4 / 20 \mathrm{~mm}$ ) natural aggregates (NA) was limestone and quartz, respectively. The recycled aggregates were made with $100 \%$ concrete, without any other construction and demolition waste products (uncontaminated). The main materials selected to produce the concrete mixes, namely OPC, fine NA, and coarse NA, were replaced with FA ( $0 \%, 30 \%$ and $60 \%)$, fine RCA $(0 \%, 50 \%$ and $100 \%)$, and coarse RCA ( $0 \%$ and $100 \%)$, respectively, individually, and jointly (Table 1$)$. In order to see the effect of the water-to-cement ratio, half of the concrete mixes $\left(\mathrm{M}_{\mathrm{sp}}\right)$ were repeated with SP (1\% of binder's mass). Moreover, the water-to-binder ratio of traditional concrete without (M1) and with SP (M1sp) were 0.53 and 0.40, respectively. The binders' amount (OPC and FA) of all concrete mixes was kept constant $\left(350 \mathrm{~kg} / \mathrm{m}^{3}\right)$. As shown in [28], the target workability of the concrete mixes (S2) was kept constant by maintaining the effective water-to-cement ratio. Further details regarding the mix compositions, the raw materials used, and the standards followed are shown in previous studies $[20,28,29]$.

Table 1. Mixes composition; RCA: recycled concrete aggregates; FA: fly ash.

\begin{tabular}{cccccccc}
\hline \multirow{2}{*}{ RCA (\%) } & Coarse RCA & \multicolumn{5}{c}{$\mathbf{0}$} & $\mathbf{1 0 0}$ \\
\cline { 2 - 8 } & Fine RCA & $\mathbf{0}$ & $\mathbf{5 0}$ & $\mathbf{1 0 0}$ & $\mathbf{0}$ & $\mathbf{5 0}$ & $\mathbf{1 0 0}$ \\
\hline \multirow{2}{*}{ FA (\%) } & 0 & M1 \& M1sp & M2 & M3 \& M3sp & M10 \& M10sp & M11 & M12 \& M12sp \\
& 30 & M4 & M5 \& M5sp & M6 & M13 & M14 \& M14sp & M15 \\
& 60 & M7 \& M7sp & M8 & M9 \& M9sp & M16 \& M16sp & M17 & M18 \& M18sp \\
\hline
\end{tabular}

As for the test methods and sample preparation, the compressive strength, splitting tensile strength, and modulus of elasticity were obtained in accordance with the methodology of specifications EN 12390-3 [30], EN 12390-6 [31] and LNEC E397 [32], by testing three samples of $150 \times 150 \mathrm{~mm}$, $\varnothing 150 \times 300 \mathrm{~mm}$, and $\varnothing 150 \times 300 \mathrm{~mm}$, respectively, at 28 and 365 days.

To optimize concrete mixes based on their combined mechanical behaviour, various weights were considered for each property according to its importance in concrete design, in order to determine a global mechanical performance ratio. Thus, the highest weight was considered for compressive strength, followed by modulus of elasticity and splitting tensile strength (Equation (3)).

$$
\text { Mechanical performance ratio }(\mathrm{MPR})=\left(\frac{\left(3 \times\left(\frac{f_{\mathrm{cm}, \text { cube mixes }}}{f_{\mathrm{cm}, \text { cube }} \text { reference }}\right)\right)+\left(1 \times\left(\frac{f_{\mathrm{ctm} \text { mixes }}}{f_{\mathrm{ctm} \text { reference }}}\right)\right)+\left(2 \times\left(\frac{\mathrm{E}_{\mathrm{cm} \text { mixes }}}{\mathrm{E}_{\mathrm{cm} \text { reference }}}\right)\right)}{6}\right)
$$

\subsection{Economy}

In this study, the most probable case scenario in the centre of Portugal was considered to estimate the transportation distances between the concrete mix plant and the suppliers of the materials (Figure 2). For that purpose, the selected database was obtained from a previous study [24], where the location of all the main suppliers of the raw materials and ready mix plants in Portugal was collected and documented. 


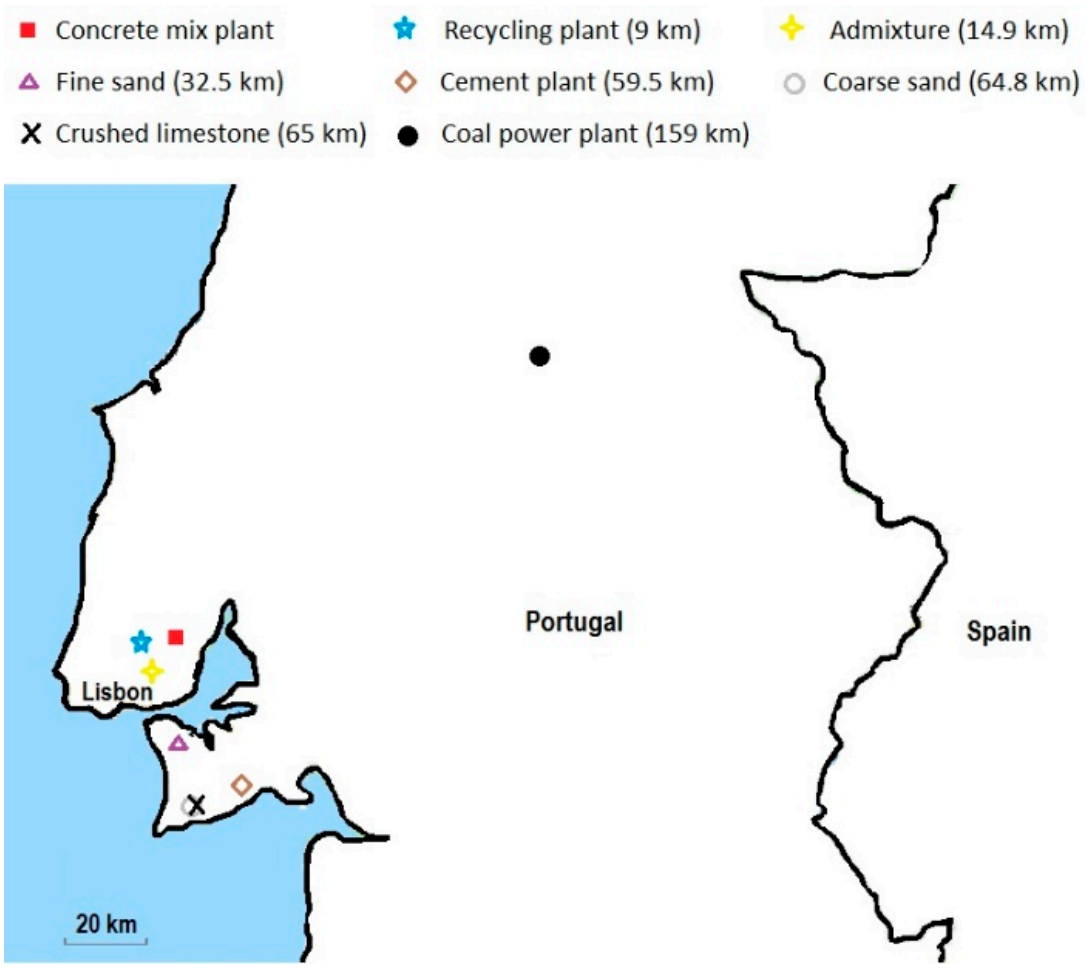

Figure 2. Transportation distances between the concrete mix plant and the material's suppliers (most common case scenario in the centre of Portugal).

The cost of each raw material was collected from Portuguese companies, and the quantity required for the production of each concrete mix was considered (Table 2). In order to consider the transportation cost of each material from the supplier to the concrete plant, the average transportation cost of Europe [33] in $2016\left(4.88 \times 10^{-05} € /\left(\mathrm{kg}^{*} \mathrm{~km}\right)\right)$ was accounted for in the final cost (Table 2). Furthermore, the amounts shown do not include value-added tax (VAT). The costs of NA, RCA, SP, and cement were adapted from Braga et al. [26], and that of FA was obtained from Teixeira et al. [34]. In addition, the results show that RCA is about two times cheaper than NA, and FA more than four times cheaper than OPC, when the cost of transportation is not considered.

Table 2. Unit cost of the raw materials; CEM I: ordinary Portland cement; SP: superplasticizers; NA: natural aggregates.

\begin{tabular}{ccccccccc}
\hline \multirow{2}{*}{ Raw Materials } & \multicolumn{7}{c}{ Unit Cost $(\boldsymbol{\epsilon} / \mathbf{k g})$} \\
\cline { 2 - 9 } & CEM I & SP & FA & Water & Fine NA & Coarse NA & Coarse RCA & Fine RCA \\
\hline Without transportation & 0.094 & 2.680 & 0.021 & 0.0015 & 0.0042 & 0.0046 & 0.002 & 0.002 \\
With transportation & 0.097 & 2.681 & 0.028 & 0.0015 & 0.0067 & 0.0078 & 0.003 & 0.003 \\
\hline
\end{tabular}

In this study, the total material costs were individually calculated for each mix, taking into account the amount of raw materials needed (including the cost of transportation), without considering the cost of the mixing procedure, company profit, VAT, etc.

By comparing the total material costs of the reference concrete $(\mathrm{C} 35 / 45)$ estimated in this study $\left(47.5 € / \mathrm{m}^{3}\right)$ with the commercial costs $\left(79.9 € / \mathrm{m}^{3}\right)$ in Portugal [35], it can be seen that, for the same strength class, the cost of commercial concrete without VAT is about $68 \%\left(32.4 € / \mathrm{m}^{3}\right)$, higher than the total material costs of concrete that was estimated without considering the cost of the mixing procedure, company profit, VAT, and so on. Thus, it was possible to calculate the total costs of the mixing procedure, company profit, etc. by replacing the total material costs of this study with the 
commercial costs (assuming that all costs, except for materials, are the same). After that, the difference between the commercial cost and the total material costs of this study was added in absolute value to all the other concrete mixes in order to obtain the final cost of $1 \mathrm{~m}^{3}$ of concrete without considering VAT.

\section{Results and Discussion}

\subsection{Strength}

Generally, the mechanical properties of concrete can be characterized by the compressive strength, tensile strength, and modulus of elasticity. In this study, these properties were obtained at 28 and 365 days (Table 3). The results show that the mechanical properties of concrete mixes made with and without SP decreased by increasing the replacement ratios of OPC and NA with FA and RCA, respectively. Furthermore, the differences between the mechanical behaviour of the reference concrete (without FA, RCA and SP) and "RCA concrete containing FA" significantly decreased over time. This is due to the pozzolanic reaction between the $\mathrm{SiO}_{2}$ of $\mathrm{FA}$ and the $\mathrm{Ca}(\mathrm{OH})_{2}$ of $\mathrm{RCA}$, which accelerates the rate of concrete strength development over time, relative to OPC concrete. The mentioned rate further increases with the use of SP, due to its dispersion effect on FA particles throughout the mixes. Consequently, the FA particles can easily reach the $\mathrm{Ca}(\mathrm{OH})_{2}$ of RCA. The reasons behind these trends are explained in previous studies $[20,29,36]$.

Table 3. Compressive strength $\left(f_{\mathrm{cm}}\right)$, splitting tensile strength $\left(f_{\mathrm{ctm}}\right)$, and modulus of elasticity $\left(\mathrm{E}_{\mathrm{cm}}\right)$ of non-conventional concrete mixes relative to the reference concrete; MPR: mechanical performance ratio.

\begin{tabular}{|c|c|c|c|c|c|c|c|c|}
\hline \multirow{2}{*}{ Mixes } & \multicolumn{2}{|c|}{$f_{\mathrm{cm}, \text { mixes }} / f_{\mathrm{cm}, \mathrm{M} 1}$} & \multicolumn{2}{|c|}{$f_{\mathrm{ctm}, \text { mixes }} / f_{\mathrm{ctm}, \mathrm{M} 1}$} & \multicolumn{2}{|c|}{$\mathrm{E}_{\mathrm{cm}, \text { mixes }} / \mathrm{E}_{\mathrm{cm}, \mathrm{M} 1}$} & \multicolumn{2}{|c|}{ MPR (\%) } \\
\hline & $28 d$ & $365 d$ & $28 d$ & $365 d$ & $28 d$ & $365 d$ & $28 d$ & $365 d$ \\
\hline $\mathrm{M} 1^{\mathrm{a}}$ & 1.00 & 1.00 & 1.00 & 1.00 & 1.00 & 1.00 & 100 & 100 \\
\hline $\mathrm{M} 1_{\mathrm{sp}}$ & 1.32 & 1.35 & 1.25 & 1.18 & 1.17 & 1.19 & 126 & 127 \\
\hline M2 & 0.83 & 0.85 & 0.89 & 0.90 & 0.89 & 0.88 & 86 & 87 \\
\hline M3 & 0.81 & 0.84 & 0.81 & 0.85 & 0.79 & 0.83 & 80 & 84 \\
\hline $\mathrm{M} 3_{\mathrm{sp}}$ & 0.97 & 1.04 & 0.91 & 0.91 & 0.91 & 0.91 & 94 & 98 \\
\hline M4 & 0.72 & 0.98 & 0.71 & 0.95 & 0.95 & 1.07 & 79 & 101 \\
\hline M5 & 0.65 & 0.93 & 0.68 & 0.95 & 0.87 & 0.99 & 73 & 95 \\
\hline $\mathrm{M} 5_{\mathrm{sp}}$ & 1.08 & 1.29 & 1.08 & 1.03 & 1.00 & 1.07 & 106 & 117 \\
\hline M6 & 0.61 & 0.88 & 0.62 & 0.87 & 0.74 & 0.92 & 65 & 89 \\
\hline M7 & 0.43 & 0.69 & 0.53 & 0.77 & 0.87 & 0.98 & 59 & 80 \\
\hline $\mathrm{M}_{\mathrm{sp}}$ & 0.76 & 0.95 & 0.90 & 0.96 & 0.93 & 1.01 & 84 & 97 \\
\hline M8 & 0.42 & 0.69 & 0.53 & 0.82 & 0.78 & 0.89 & 56 & 78 \\
\hline M9 & 0.39 & 0.65 & 0.51 & 0.79 & 0.74 & 0.88 & 52 & 75 \\
\hline $\mathrm{M} 9_{\mathrm{sp}}$ & 0.66 & 0.93 & 0.78 & 0.95 & 0.79 & 0.89 & 72 & 92 \\
\hline M10 & 0.93 & 0.97 & 0.99 & 0.99 & 0.85 & 0.88 & 91 & 94 \\
\hline $\mathrm{M} 10_{\mathrm{sp}}$ & 1.13 & 1.19 & 1.20 & 1.14 & 0.99 & 1.01 & 110 & 112 \\
\hline M11 & 0.77 & 0.83 & 0.80 & 0.82 & 0.74 & 0.77 & 76 & 81 \\
\hline M12 & 0.75 & 0.82 & 0.78 & 0.82 & 0.64 & 0.67 & 72 & 77 \\
\hline $\mathrm{M} 12_{\mathrm{sp}}$ & 0.88 & 0.99 & 0.85 & 0.89 & 0.77 & 0.76 & 84 & 90 \\
\hline M13 & 0.7 & 1.01 & 0.68 & 0.96 & 0.79 & 0.91 & 73 & 97 \\
\hline M14 & 0.59 & 0.92 & 0.57 & 0.84 & 0.74 & 0.85 & 64 & 88 \\
\hline $\mathrm{M}_{14} 4_{\mathrm{sp}}$ & 0.96 & 1.21 & 0.89 & 0.87 & 0.87 & 0.94 & 92 & 106 \\
\hline M15 & 0.59 & 0.87 & 0.56 & 0.83 & 0.68 & 0.81 & 61 & 84 \\
\hline M16 & 0.41 & 0.67 & 0.50 & 0.78 & 0.75 & 0.87 & 54 & 76 \\
\hline $\mathrm{M} 16_{\mathrm{sp}}$ & 0.68 & 0.96 & 0.82 & 0.94 & 0.87 & 0.93 & 77 & 95 \\
\hline M17 & 0.38 & 0.63 & 0.40 & 0.63 & 0.67 & 0.78 & 48 & 68 \\
\hline M18 & 0.38 & 0.62 & 0.41 & 0.65 & 0.61 & 0.75 & 46 & 67 \\
\hline $\mathrm{M} 18_{\mathrm{sp}}$ & 0.58 & 0.88 & 0.61 & 0.77 & 0.69 & 0.76 & 62 & 82 \\
\hline
\end{tabular}

a The mix M1 was considered the reference concrete for all relative values. Its compressive strength, splitting tensile strength, and modulus of elasticity were $55.8 \mathrm{MPa}, 4.28 \mathrm{MPa}$, and $43.8 \mathrm{GPa}$ at 28 days, and $61.3 \mathrm{MPa}, 4.7 \mathrm{MPa}$, and $47.0 \mathrm{GPa}$ at 365 days, respectively. 
According to the MPR values (calculated according to Equation (3)) at early and longer ages, the conventional mixes with SP had the highest mechanical performance, followed by the mixes containing low volumes of FA and coarse RCA (Figure 3). The lowest ranking concrete mixes are those containing high volumes of FA or fine RCA. These trends were expected because it is well-known that SP increases the mechanical performance of concrete, and both FA and RCA are harmful above a given incorporation ratio. Additionally, a high volume of coarse RCA in concrete is less detrimental than that of fine RCA, but much less favorable than the incorporation of FA $[20,29,36]$. Although the mechanical behaviour of concrete is essential, ranking concrete mixes based only on their strength may not be reliable from a "business as usual" point of view. In fact, the cost of concrete cannot be ignored when selecting the strength class, and they must be jointly optimized according to the target application. Therefore, an economic life cycle assessment was made for all concrete mixes (Section 3.2).

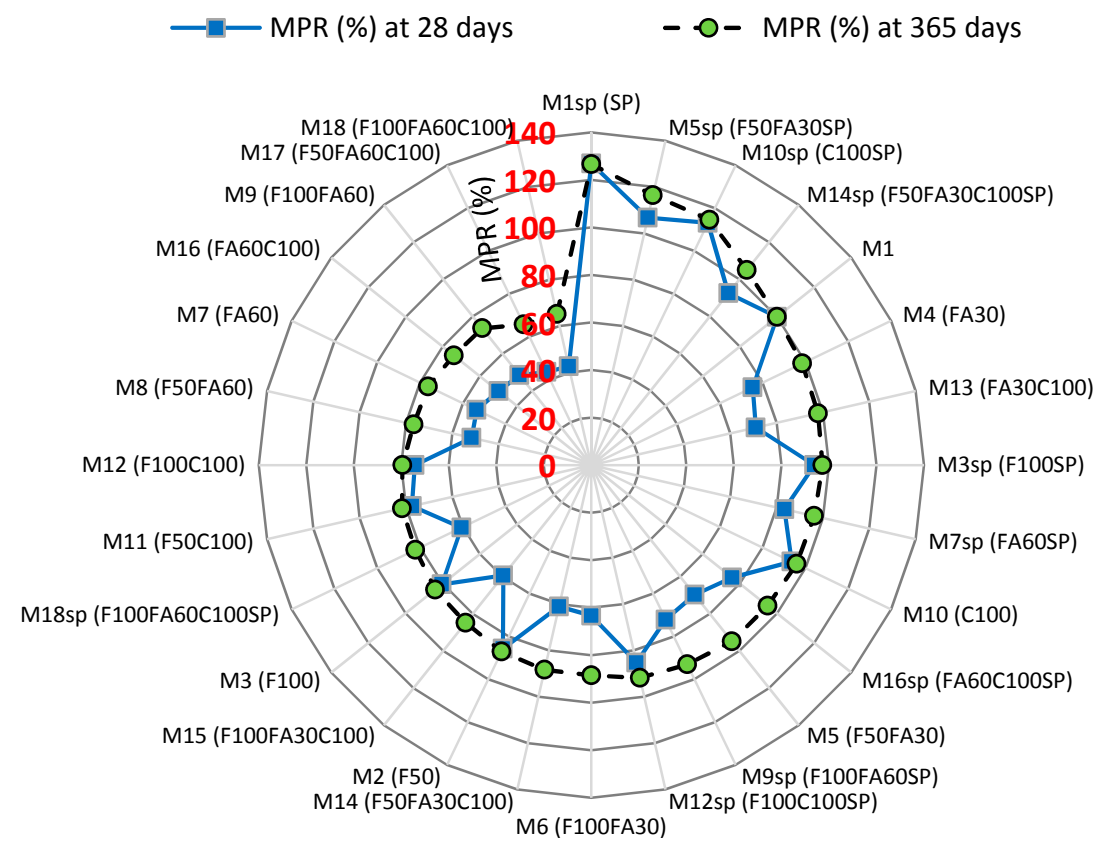

Figure 3. Ranking the concrete mixes based on the mechanical performance ratio (MPR) at 28 and 365 days.

\subsection{Economy}

The data for economic assessment varies considerably between regions. This is because local conditions highly affect the cost of labour and market costs of recovered materials. Regulatory constraints and regional financial conditions also limit the economic viability of selective demolition in a free market. Considering this evidence, the economic implications of concrete mixes made with various incorporation ratios of FA and RCA, both with and without SP, were assessed by analysing a case study in Portugal (Table 4).

The results show that the cost of the concrete mixes decreased slightly with the incorporation of RCA (up to $4 \%$ with fine RCA, and 7\% with coarse RCA, contents). Furthermore, the cost decreased by $9 \%$ and $18 \%$ when OPC was replaced by $30 \%$ and $60 \%$ of FA, respectively. Contrary to the incorporation of RCA and FA, the use of $1 \%$ SP led to about a 13\% higher cost. However, the results show that by incorporating $60 \%$ of FA in NA concrete or by incorporating 30\% of FA in RCA concrete, the high cost of concrete with SP can be offset. In addition, by incorporating RCA in FA concrete, even when SP is used, the cost is lower than that of the reference concrete (Figure 4). Bearing this in mind, it is not reliable to directly compare the cost of concrete mixes when their performances are different 
(Section 1). Therefore, the cost efficiency of the concrete mixes is studied in Section 3.3 by considering their mechanical performance.

Table 4. Cost of $1 \mathrm{~m}^{3}$ of each concrete mix.

\begin{tabular}{|c|c|c|c|c|c|c|c|c|c|c|c|c|}
\hline \multirow{2}{*}{ Mixes } & \multirow{2}{*}{ Characteristics $^{\text {a }}$} & \multicolumn{11}{|c|}{$\operatorname{Cost}\left(€ / \mathrm{m}^{3}\right)$} \\
\hline & & CEM I & SP & FA & Water & $\begin{array}{l}\text { Fine } \\
\text { NA }\end{array}$ & $\begin{array}{c}\text { Coarse } \\
\text { NA }\end{array}$ & $\begin{array}{l}\text { Coarse } \\
\text { RCA }\end{array}$ & $\begin{array}{l}\text { Fine } \\
\text { RCA }\end{array}$ & $\begin{array}{c}\text { Total Material } \\
\text { Cost }^{\mathrm{b}}\end{array}$ & $\begin{array}{c}\text { Final } \\
\text { Cost } b, c\end{array}$ & $\Delta$ \\
\hline M1 & COFOFA0 & 33.93 & & & 0.28 & 5.1 & 8.23 & & & 47.54 & 79.93 & 1.00 \\
\hline M2 & C0F50FA0 & 33.93 & & & 0.31 & 2.5 & 8.12 & & 1.03 & 45.89 & 78.28 & 0.98 \\
\hline M3 & C0F100FA0 & 33.93 & & & 0.34 & & 8.03 & & 2.04 & 44.34 & 76.73 & 0.96 \\
\hline M4 & COFOFA30 & 23.75 & & 2.92 & 0.27 & 4.99 & 8.28 & & & 40.20 & 72.60 & 0.91 \\
\hline M5 & C0F50FA30 & 23.75 & & 2.92 & 0.3 & 2.44 & 8.18 & & 1.01 & 38.60 & 70.99 & 0.89 \\
\hline M6 & C0F100FA30 & 23.75 & & 2.92 & 0.33 & & 8.06 & & 1.98 & 37.04 & 69.43 & 0.87 \\
\hline M7 & C0F0FA60 & 13.57 & & 5.84 & 0.26 & 4.86 & 8.34 & & & 32.87 & 65.27 & 0.82 \\
\hline M8 & C0F50FA60 & 13.57 & & 5.84 & 0.29 & 2.48 & 8 & & 1.02 & 31.20 & 63.59 & 0.80 \\
\hline M9 & C0F100FA60 & 13.57 & & 5.84 & 0.32 & & 8.12 & & 1.93 & 29.78 & 62.17 & 0.78 \\
\hline M10 & C100F0FA0 & 33.93 & & & 0.3 & 5.07 & & 2.96 & & 42.26 & 74.65 & 0.93 \\
\hline M11 & C100F50FA0 & 33.93 & & & 0.33 & 2.49 & & 2.92 & 1.02 & 40.69 & 73.09 & 0.91 \\
\hline M12 & C100F100FA0 & 33.93 & & & 0.36 & & & 2.89 & 2.03 & 39.20 & 71.59 & 0.90 \\
\hline M13 & C100F0FA30 & 23.75 & & 2.92 & 0.29 & 4.95 & & 2.98 & & 34.89 & 67.28 & 0.84 \\
\hline M14 & C100F50FA30 & 23.75 & & 2.92 & 0.33 & 2.43 & & 2.94 & 1 & 33.36 & 65.76 & 0.82 \\
\hline M15 & C100F100FA30 & 23.75 & & 2.92 & 0.35 & & & 2.89 & 1.97 & 31.88 & 64.27 & 0.80 \\
\hline M16 & C100F0FA60 & 13.57 & & 5.84 & 0.28 & 4.82 & & 3 & & 27.52 & 59.91 & 0.75 \\
\hline M17 & C100F50FA60 & 13.57 & & 5.84 & 0.31 & 2.37 & & 2.96 & 0.98 & 26.03 & 58.42 & 0.73 \\
\hline M18 & C100F100FA60 & 13.57 & & 5.84 & 0.35 & & & 2.92 & 1.91 & 24.60 & 56.99 & 0.71 \\
\hline M1sp & COFOFA0SP & 33.93 & 9.38 & & 0.21 & 5.5 & 8.7 & & & 57.73 & 90.12 & 1.13 \\
\hline M3sp & C0F100FA0SP & 33.93 & 9.38 & & 0.27 & & 8.52 & & 2.2 & 54.30 & 86.69 & 1.08 \\
\hline M5sp & C0F50FA30SP & 23.75 & 9.38 & 2.92 & 0.23 & 2.65 & 8.65 & & 1.09 & 48.66 & 81.06 & 1.01 \\
\hline M7sp & C0F0FA60SP & 13.57 & 9.38 & 5.84 & 0.19 & 5.19 & 8.91 & & & 43.08 & 75.48 & 0.94 \\
\hline M9sp & C0F100FA60SP & 13.57 & 9.38 & 5.84 & 0.25 & & 8.6 & & 2.09 & 39.74 & 72.13 & 0.90 \\
\hline M10sp & C100F0FA0SP & 33.93 & 9.38 & & 0.24 & 5.48 & & 3.13 & & 52.15 & 84.55 & 1.06 \\
\hline M12sp & C100F100FA0SP & 33.93 & 9.38 & & 0.29 & & & 3.06 & 2.19 & 48.85 & 81.24 & 1.02 \\
\hline M14sp & C100F50FA30SP & 23.75 & 9.38 & 2.92 & 0.26 & 2.63 & & 3.11 & 1.08 & 43.13 & 75.53 & 0.94 \\
\hline M16sp & C100F0FA60SP & 13.57 & 9.38 & 5.84 & 0.21 & 5.23 & & 3.18 & & 37.40 & 69.80 & 0.87 \\
\hline M18sp & C100F100FA60SP & 13.57 & 9.38 & 5.84 & 0.28 & & & 3.1 & 2.07 & 34.25 & 66.64 & 0.83 \\
\hline
\end{tabular}

a F-fine RCA\%; C-coarse RCA\%; FA—fly ash\%; SP—superplasticizer; ${ }^{\mathrm{b}}$ The difference between "total material's costs" and "final cost" is explained in Section $2.2 ;{ }^{\mathrm{C}}$ Without VAT.

A study by Braga et al. [26] estimated the average cost of NA and RCA concrete according to 23 and 20 international studies, respectively. It shows that, for strength class C30/37 and C50/60, the average costs were $43 € / \mathrm{m}^{3}$ and $57 € / \mathrm{m}^{3}$, respectively. These values were lower than those of the total material costs, final costs of this study and the commercial cost of concrete. This is due to the fact that the mentioned study estimated the cost of concrete mixes without considering the cost of the mixing procedure, company profit, and more. As with this study, it showed that the cost slightly decreased ( $42 € / \mathrm{m}^{3}$ for $\mathrm{C} 30 / 37$ and $48 € / \mathrm{m}^{3}$ for C50/60) when RCA was used. Furthermore, other studies $[5,37,38]$ reported that the cost of concrete significantly decreased by using FA.

Figure 5 presents the relationship between compressive strength and cost of $1 \mathrm{~m}^{3}$ of concrete for the concrete mixes in this study (M1-M18sp) and commercial concrete mixes obtained from Portuguese suppliers [35]. There is a strong relationship between the two parameters with a determination coefficient of 0.90 and 0.99 for concrete mixes obtained by the current study and Portuguese suppliers.

Generally, the price of raw materials depends on the region and supplier. Therefore, Equation (4) is proposed to compare the results of the reference concrete with those of the other mixes made with various incorporation ratios of FA and RCA, with or without SP, even if the price of these raw materials changes. As seen in Figure 6, the results can be represented by the line of equality with a high coefficient of determination $\left(R^{2}=0.98\right)$.

$$
\mathrm{C}_{\text {mixes }}=\mathrm{C}_{\text {ref. }}+2 *\left(5 \cdot F A \% \cdot \mathrm{C}_{F A}+8 \cdot \text { Coarse } R C A \% \cdot \mathrm{C}_{\text {coarse } R C A}+5 \cdot \text { fine } R C A \% \cdot \mathrm{C}_{\text {fine }} R C A-3 \cdot S P \% \cdot \mathrm{C}_{S P}\right)
$$

where $\mathrm{C}_{\text {mixes }}$, and $\mathrm{C}_{\text {ref., }}$ is the cost of $1 \mathrm{~m}^{3}$ of other mix and of the reference concrete "M1"; $\mathrm{FA} \%$, Coarse $R C A \%$. fine $R C A \%$ and $S P \%$ are the incorporation ratios of these raw materials; $C_{F A}$, $\mathrm{C}_{\text {coarse } R C A}, \mathrm{C}_{\text {fine }} \mathrm{RCA}$ and $\mathrm{C}_{S P}$ is the cost of $1 \mathrm{~kg}$ of these raw materials. 


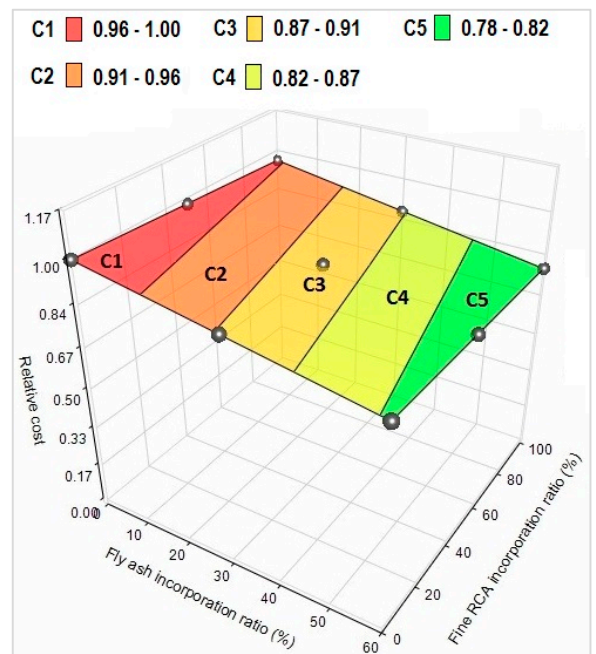

(a)
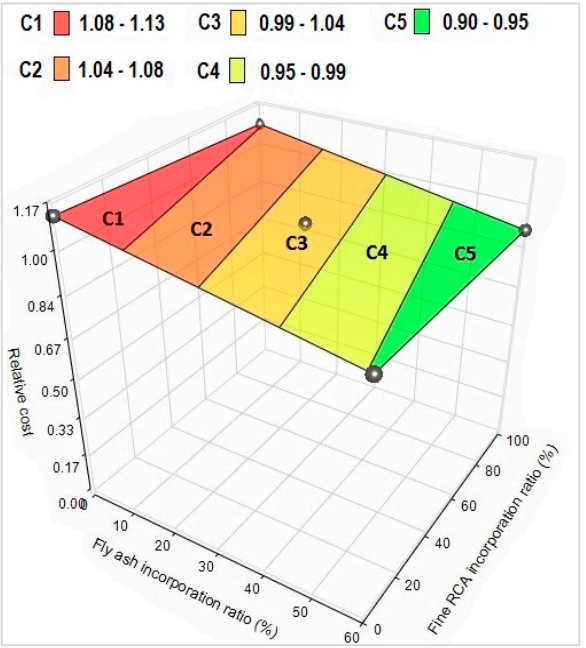

(c)

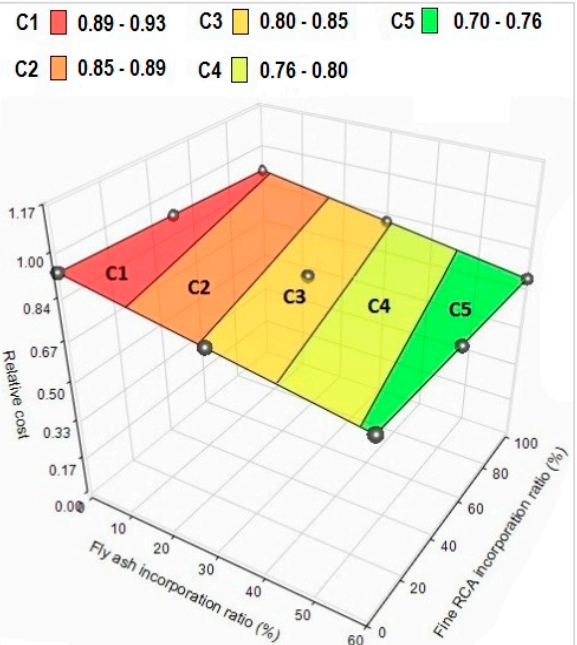

(b)

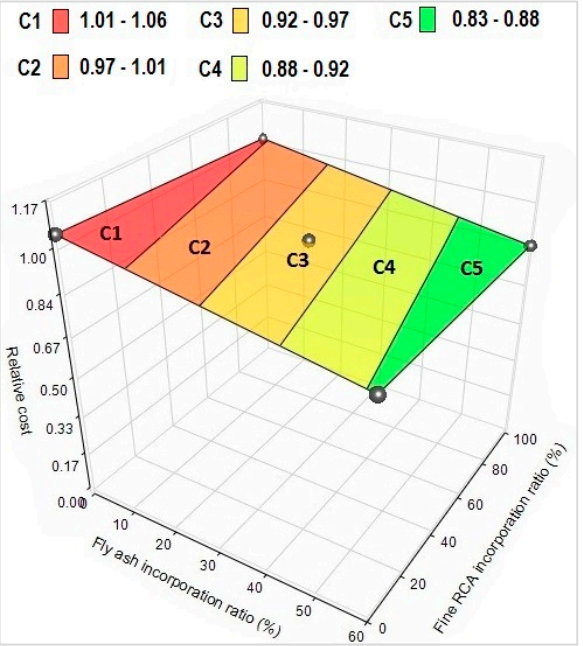

(d)

Figure 4. Relative cost of $1 \mathrm{~m}^{3}$ concrete mixes with increasing incorporation levels of fine RCA and FA with (a) $0 \%$ and $0 \%$ (b) $100 \%$ and $0 \%$, (c) $0 \%$ and $1 \%$, and (d) $100 \%$ and $1 \%$ of coarse RCA and $\mathrm{SP}$, respectively. All figures are relative to the reference concrete "M1". (Black dots represent relative results; shades represent relative cost).

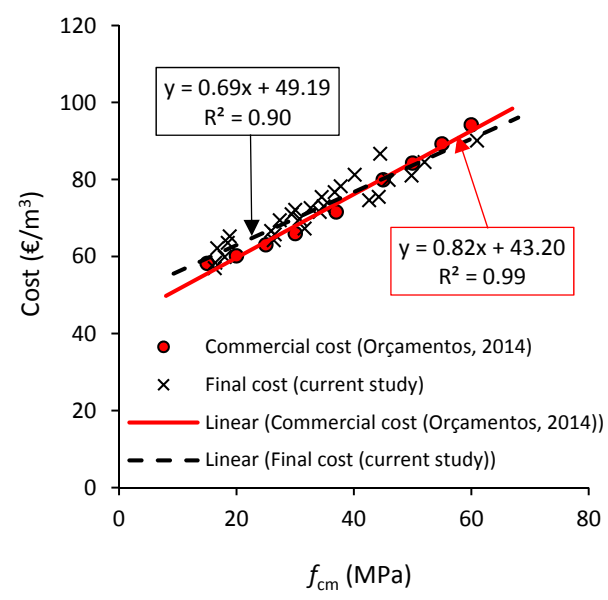

Figure 5. Relationship between compressive strength at 28 days and cost of $1 \mathrm{~m}^{3}$ of concrete. $f_{\mathrm{cm}, \text { cube }}$ was converted to $f_{\mathrm{cm}}$ according to EN 1992-1-1 [39]. 


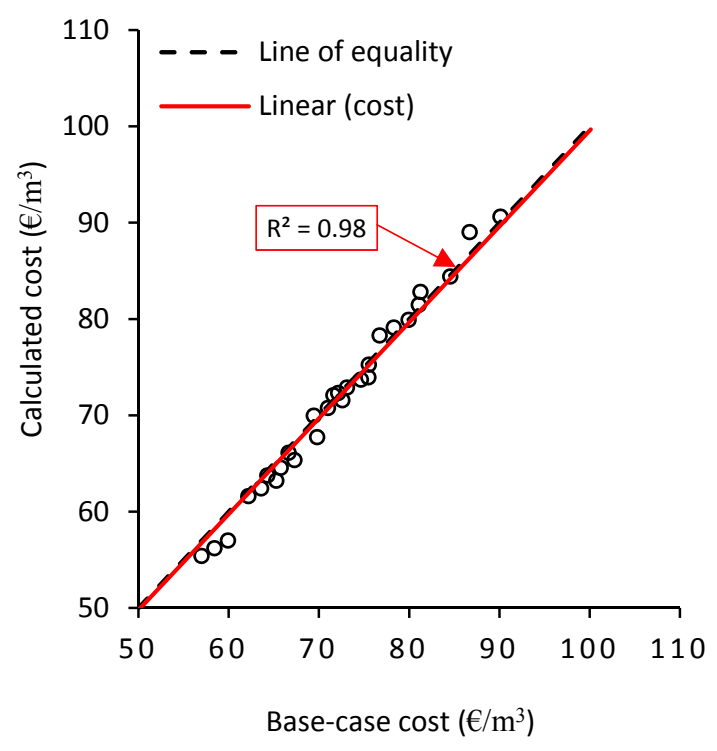

Figure 6. Base-case cost versus calculated cost.

Figure 7 shows the importance of considering the cost and compressive strength simultaneously to select concrete mixes based on the target application. The cost and compressive strength of the concrete mixes with conventional concrete (M1) are compared. For example, M13 presents a similar strength value but a lower cost than that of conventional concrete. On the contrary, M5sp has a similar cost but a higher strength. Finally, the selection of one of the others concrete mixes depends on the selected application. For example, the mixes located in "lower cost and lower strength" zone are preferable for residential houses, and the mixes located in "higher cost and higher strength" zone for high-rise buildings. However, to select suitable mixes within each of these sub-groups, it is important to make a more comprehensive cost efficiency optimisation considering cost and MPR, such as proposed in Section 3.3.

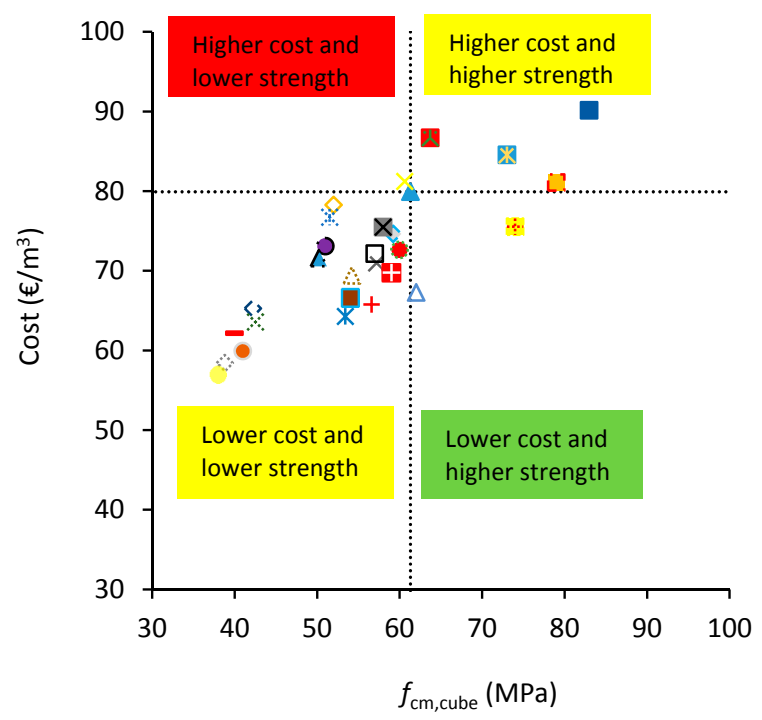

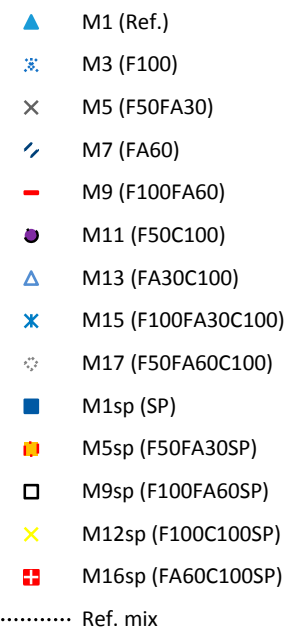

... M3 (F100)

M5 (F50FA30)

$\mathrm{M} 7$ (FA60)

M9 (F100FA60)

M11 (F50C100)

M13 (FA30C100)

(F100FA30C100)

- M1sp (SP)

i. M5sp (F50FA30SP)

M9sp (F100FA60SP)

M12sp (F100C100SP) Ref. mix $\checkmark \quad \mathrm{M} 2$ (F50)

- M4 (FA30)

$\therefore \quad$ M6 (F100FA30)

$\therefore \quad$ M8 (F50FA60)

$\triangle \quad M 10$ (C100)

A $\mathrm{M} 12$ (F100C100)

$+\quad$ M14 (F50FA30C100)

- M16 (FA60C100)

M18 (F100FA60C100)

- M3sp (F100SP)

× M7sp (FA60SP)

M10sp (C100SP)

: M14sp (F50FA30C100SP)

n18sp (F100FA60C100SP)

Figure 7. Relationship between compressive strength at 365 days and cost of $1 \mathrm{~m}^{3}$ of concrete. The mixes are divided into four zones according to the cost and strength of reference concrete (M1). 


\subsection{Optimization}

Generally, the optimization process of concrete depends on its application. Therefore, ranking concrete only according to economy or mechanical properties is not reasonable. This study thus considered a business as usual scenario (i.e., the least cost possible for a given durability and mechanical performance), and the optimum concrete may be one that has a moderate performance in both characteristics. For this reason, two zones (cost-efficient and cost-inefficient) were considered and separated by the line equivalent to the reference concrete (Figure 8).
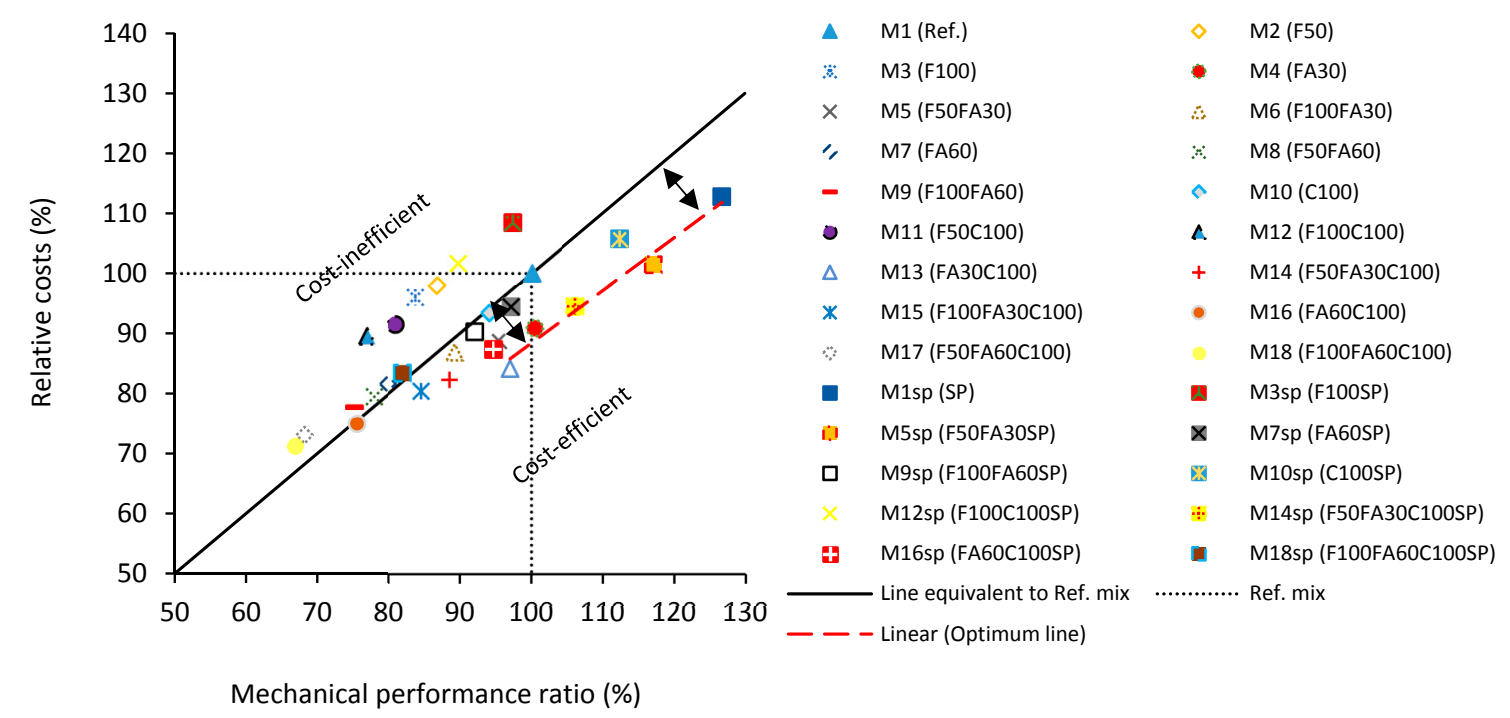

Figure 8. Relationship between relative cost and mechanical performance ratio of concrete mixes made with (square signs) and without (other signs) SP, regardless of the binders and aggregates used. FA, F, C, and SP stand for fly ash, fine RCA, coarse RCA, and superplasticizer, respectively, and the values are their incorporation level in the mixes.

Mixes were optimized by comparing their MPR at longer ages (365 days) with their cost. The reason for which longer ages were considered is that at early ages, the full potential properties of the mixes containing FA widely differs from that of the mixes made with OPC only, due to the delayed hydration process of the former [36].

Apart from the fact that SP significantly increases the cost (Section 3.2), all the mixes (with and without FA and RCA) made with SP are in the suitable zone (cost-efficient) in terms of mechanical and cost characteristics, except those containing $100 \%$ of fine RCA (Figure 8 ). Therefore, the use of SP is highly cost-efficient. The reasons for decreased performance of SP with the use of high volume of fine RCA have been previously discussed in Kurad et al. [25]. Additionally, most of the optimum mixes (optimum line) are those made with SP (as explained in the next paragraphs).

Figure 9a,b show the effect of incorporating FA and RCA, respectively, on the relationship between the relative cost and mechanical performance ratio of the mixes previously shown in Figure 8 . The results show that the NA concrete containing $30 \%$ of FA has a slightly better mechanical performance and lower cost than those of the reference concrete. For mixes containing a high volume of FA, the mechanical performance decreased by up to $20 \%$. However, according to the weights considered in this study, the mixes mentioned are suitable for some specific application (e.g., residential housing), because their cost decreased about the same percentage as their strength. Regarding mixes containing RCA, low incorporation FA (M5, M6, M14, M15, M5sp and M14sp in Figure 8) is advisable, since the corresponding mixes are all located in the suitable zone (cost-efficient) in terms of mechanical and cost characteristics. A high volume of FA can be also used with RCA concrete (M9 and M9sp in Figure 8). However, most of the mixes are located near the line between the suitable and unsuitable 
zones (Figure 9a). In addition, the mentioned hypotheses concerning the lower cost of concrete mixes produced with both FA and RCA can only be confirmed when the application of non-traditional materials becomes more common in construction practice.

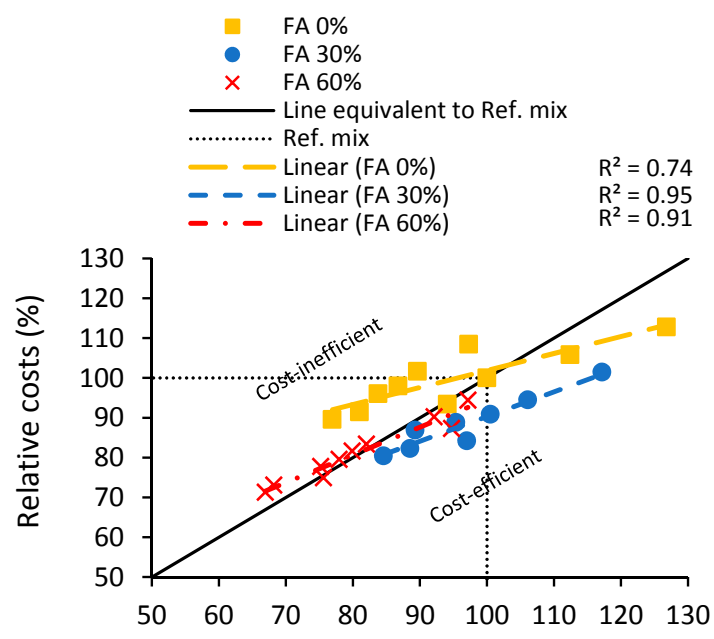

(a)

$$
\text { Mechanical performance ratio (\%) }
$$

Figure 9. Relationship between relative cost and mechanical performances ratio of mixes classified based on the incorporation ratio of (a) FA (regardless of the type and ratio of the aggregates) and (b) RCA (regardless of the type and ratio of the binders).

Concerning the effect of RCA on the mechanical and cost characteristics of concrete, the results show that mixes only with coarse RCA are all located in the suitable zone (M10 and M10sp in Figure 8). However, for fine RCA, it depends on its incorporation ratio in concrete. The incorporation of RCA can be considered as suitable up to 50\% (M5 and M14 in Figure 8) (Figure 9b). Higher incorporation ratios of fine RCA are not so advisable, even if FA and SP are simultaneously incorporated in the mix.

In Figure 8, the optimum mixes were selected based on their distance from the "line equivalent to the reference mix" in the cost-efficient zone, since this distance is proportional to their cost-efficiency. In other words, compared to that line, the optimum mixes were those with higher MPR-to cost-ratio (e.g., equivalent costs and superior mechanical behaviour, or equivalent mechanical behaviour but lower cost). For example, from the cost-efficient concrete mixes, the following ones can be considered as optimum: $\mathrm{M} 1_{\mathrm{sp}}, \mathrm{M} 5_{\mathrm{sp}}, \mathrm{M} 14_{\mathrm{sp}}, \mathrm{M} 4$ and M13, which were mostly made by incorporating FA, RCA, and SP simultaneously. Furthermore, it is possible to consider M14 $4_{\mathrm{sp}}(100 \%$ coarse RCA, $50 \%$ fine RCA, 30\% FA, 1\% SP) as the best mix among the optimum mixes, because its strength is higher than that of the reference mix (M1) and its cost is lower. In addition, M4 (30\% FA) is considered to be the second-best due the same reason. These results agree with the literature (Section 1) that shows that it is wrong to optimize concrete mixes based on their strength (Figure 3) or cost (Figure 4) individually.

In order to confirm these findings, this study presents a relationship between the "MPR-to-cost ratio" and the compressive strength $\left(f_{\mathrm{cm}, \mathrm{cube}}\right)$ of the concrete mixes (Figure 10). The compressive strength ( $x$-axis) is considered because it is the most demanded characteristic of concrete in the construction industry. Since the optimization of concrete depends on its application, this chart can be useful when a minimum compressive strength is considered to select the optimum mix. For example, high-strength concrete may not be required for residential houses. As concluded before, the following mixes (M1sp, M5sp, M14sp, M4 and M13) can be considered as optimum because their "MPR-to-cost ratio" values is higher compared to other mixes. Again, apart from the fact that the SP increases the cost of concrete, most of the mixes made with SP are above the reference line and are therefore more cost-efficient than M1 (M1sp, M5sp, M7sp, M9sp, M10sp, M14sp and M16sp). Thus, the use of SP is highly cost-efficient. In other words, mixes with high-strength are more cost-efficient than low-strength 
concrete. In that case, it is worth paying more to increase the strength of concrete, since this investment has a higher return. In addition, the cost efficiency of the coarse RCA concrete is significantly higher than that of the fine RCA concrete (e.g., M13 versus M6; M16sp versus M16sp). Furthermore, concrete with an incorporation of FA can be considered as cost-efficient, and the high incorporation of FA are even more cost-efficient when SP used.
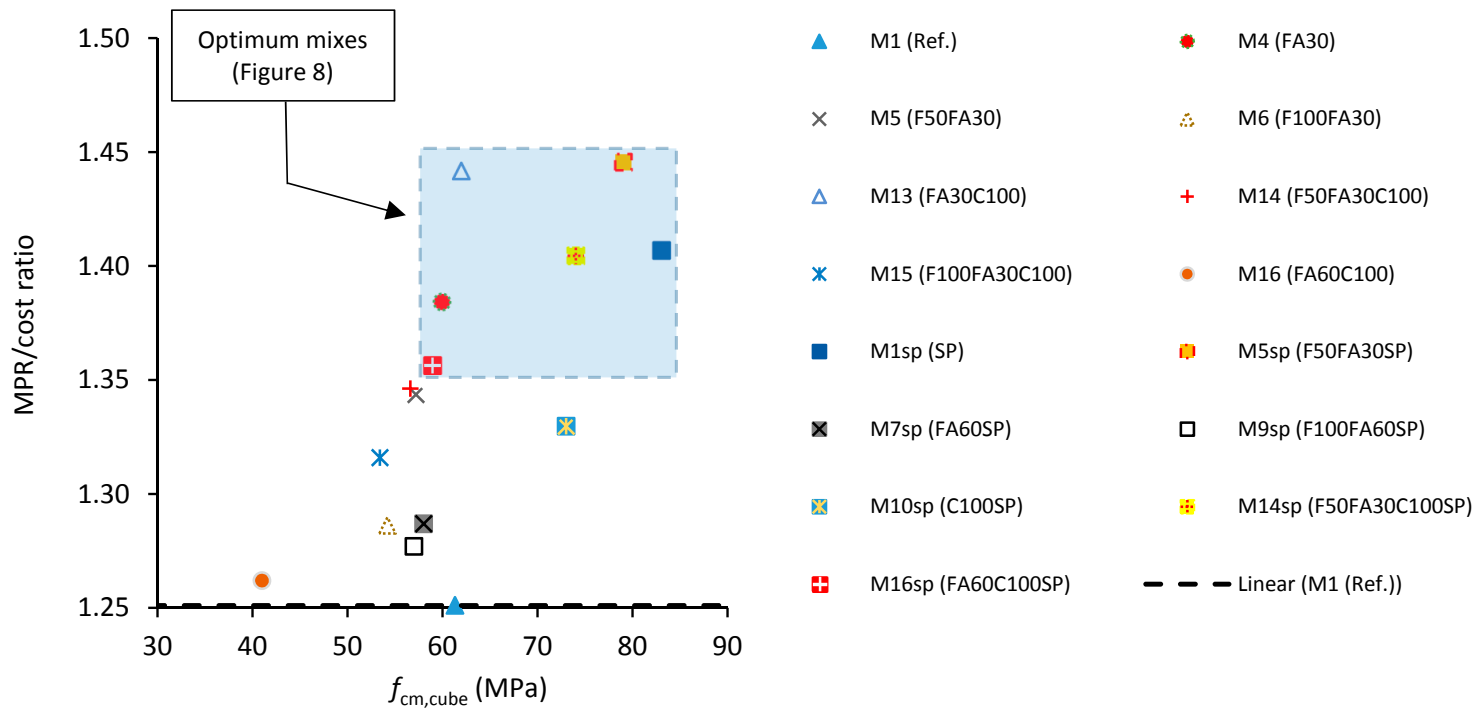

Figure 10. Compressive strength versus "MPR-cost ratio" of the concrete mixes.

\section{Conclusions}

This study allows a better understanding of the mechanical and cost characteristics of mixes made with high amounts of FA and RCA, both with and without SP. The following conclusions can be drawn from this study:

- Mechanical characteristics: both FA and RCA are detrimental to the mechanical properties of concrete, namely compressive strength, splitting tensile strength, and modulus of elasticity. The compressive strength and splitting tensile strength mostly decrease with the incorporation of FA, and the modulus of elasticity is mostly affected by the use of RCA. After a given age, the strength development for all the mentioned properties increased over time, for mixes containing both FA and RCA, relative to OPC only mixes. The strength development of the mixes containing FA and RCA further accelerated with the use of SP. Thus, the simultaneous use of FA and RCA in concrete also containing SP is highly advisable;

- Economic assessment of the concrete mixes: the cost of the concrete mixes slightly decreased with the incorporation of RCA. On the contrary, the use of a small percentage of SP significantly increased the cost. However, by incorporating either $60 \%$ of FA in NA concrete or $30 \%$ of FA in RCA concrete, the high cost of concrete with SP can be offset. In addition, by incorporating RCA in FA concrete, even when SP is used, the cost is lower than that of reference concrete. However, the conclusions are not to be generalized because the results may be different for other approaches or assumed scenarios in life cycle inventory modelling, as well as other regions than Portugal;

- Optimization. The optimum mixes regarding economy (cost-efficient) are not necessarily those with the lowest cost. Currently, the mechanical characteristics of mixes are also an essential factor to aid decision on the optimum concrete. The cost of concrete mixes significantly increases with the use of SP. However, all the mixes (regardless of the type of binder and aggregates) with SP are considered as suitable solutions (located in the cost-efficient zone, i.e., more cost-efficient that the reference mix) except when $100 \%$ of fine RCA is used individually or jointly with $100 \%$ of coarse RCA. A low volume of FA is highly advisable in terms of mechanical behaviour and 
cost. Although a high volume of FA significantly decreases the mechanical characteristics of concrete, those mixes are still considered suitable (located in the cost-efficient zone) when SP is used, due to their significant decrease in cost. Concrete mixes with coarse RCA can be considered as cost-efficient. However, the suitability of fine RCA concrete regarding the cost and mechanical characteristics depends on its incorporation ratio. In fact, it is not advisable to use high volumes of fine RCA without FA in concrete, because of the high loss in mechanical performance. Finally, the results show that the optimum mixes in terms of cost and mechanical characteristics are mostly the ones made with simultaneous incorporation of RCA, FA, and SP, rather than with their individual incorporation.

Author Contributions: R.K., J.d.B., and J.D.S. conceived and designed the experiments; R.K. analyzed the data; R.K. wrote the paper and J.d.B. and J.D.S. revised it.

Funding: This research received no external funding.

Acknowledgments: The authors acknowledge the support of CERIS unit from IST-University of Lisbon and the Foundation for Science and Technology of Portugal.

Conflicts of Interest: The authors declare no conflict of interest. The founding sponsors had no role in the design of the study; in the collection, analyses, or interpretation of data; in the writing of the manuscript, and in the decision to publish the results.

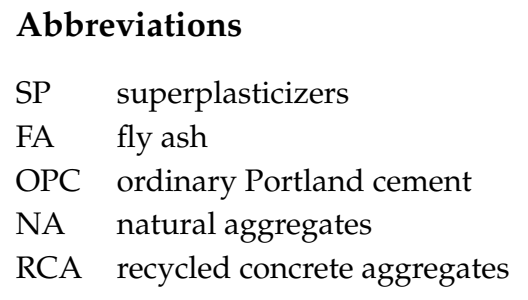

\section{References}

1. Turner and Townsed. Overstretched and over-reliant: A polarised market. In International Construction Market Survey; Turner and Townsed: Leeds, UK, 2016; 84p.

2. Silva, R.V.; de Brito, J.; Evangelista, L.; Dhir, R.K. Design of reinforced recycled aggregate concrete elements in conformity with Eurocode 2. Constr. Build. Mater. 2016, 105, 144-156. [CrossRef]

3. Adasooriya, N.; Samarakoon, S.; Gudmestad, O. Corrosion propagation phase and bond strength degradation of reinforced concrete structures: State of the art. Int. J. Comput. Methods Exp. Meas. 2018, 6, 499-514. [CrossRef]

4. Silva, P.R.; de Brito, J. Experimental study of the porosity and microstructure of self-compacting concrete (SCC) with binary and ternary mixes of fly ash and limestone filler. Constr. Build. Mater. 2015, 86, 101-112. [CrossRef]

5. Rashad, A.M. An exploratory study on high-volume fly ash concrete incorporating silica fume subjected to thermal loads. J. Clean. Prod. 2015, 87, 735-744. [CrossRef]

6. Rashad, A.M. A brief on high-volume class F fly ash as cement replacement-A guide for Civil Engineer. Int. J. Sustain. Built Environ. 2015, 4, 278-306. [CrossRef]

7. Dragaš, J.; Ignjatović, I.; Tošić, N.; Marinković, S. Mechanical and time-dependent properties of high-volume fly ash concrete for structural use. Mag. Concr. Res. 2016, 68, 632-645. [CrossRef]

8. Thomas, C.; Setién, J.; Polanco, J.A.; Alaejos, P.; de Juan, M.S. Durability of recycled aggregate concrete. Constr. Build. Mater. 2013, 40, 1054-1065. [CrossRef]

9. Xuan, D.; Zhan, B.; Poon, C.S. Durability of recycled aggregate concrete prepared with carbonated recycled concrete aggregates. Cem. Concr. Compos. 2017, 84, 214-221. [CrossRef]

10. De Brito, J.; Kurda, R.; da Silva, P.R. Can we truly predict the compressive strength of concrete without knowing the properties of aggregates? Appl. Sci. 2018, 8, 1095. [CrossRef]

11. Thomas, C.; Setién, J.; Polanco, J.A.; Cimentada, A.I.; Medina, C. Influence of curing conditions on recycled aggregate concrete. Constr. Build. Mater. 2018, 172, 618-625. [CrossRef]

12. Golafshani, E.M.; Behnood, A. Application of soft computing methods for predicting the elastic modulus of recycled aggregate concrete. J. Clean. Prod. 2018, 176, 1163-1176. [CrossRef] 
13. Pedro, D.; de Brito, J.; Evangelista, L. Evaluation of high-performance concrete with recycled aggregates: Use of densified silica fume as cement replacement. Constr. Build. Mater. 2017, 147, 803-814. [CrossRef]

14. Pacheco, J.; de Brito, J.; Ferreira, J.; Soares, D. Flexural load tests of full-scale recycled aggregates concrete structures. Constr. Build. Mater. 2015, 101, 65-71. [CrossRef]

15. Silva, R.V.; de Brito, J.; Dhir, R.K. Properties and composition of recycled aggregates from construction and demolition waste suitable for concrete production. Constr. Build. Mater. 2014, 65, 201-217. [CrossRef]

16. Tangchirapat, W.; Rattanashotinunt, C.; Buranasing, R.; Jaturapitakkul, C. Influence of fly ash on slump loss and strength of concrete fully incorporating recycled concrete aggregates. J. Mater. Civ. Eng. 2013, 25, 243-251. [CrossRef]

17. Tošić, N.D.; Marinković, S.B.; Ignjatović, I.S.; Bajat, B.J.; Pejović, M.P. Experimental Setup for Measuring Long-Term Behavior of Green Reinforced Concrete Beams; Springer International Publishing: Cham, Switzerland, 2018.

18. Kou, S.; Poon, C. Long-term mechanical and durability properties of recycled aggregate concrete prepared with the incorporation of fly ash. Cem. Concr. Compos. 2013, 37, 12-19. [CrossRef]

19. Tošić, N.; Marinković, S.; Pecić, N.; Ignjatović, I.; Dragaš, J. Long-term behaviour of reinforced beams made with natural or recycled aggregate concrete and high-volume fly ash concrete. Constr. Build. Mater. 2018, 176, 344-358. [CrossRef]

20. Kurad, R.; Silvestre, J.D.; de Brito, J.; Ahmed, H. Effect of incorporation of high volume of recycled concrete aggregates and fly ash on the strength and global warming potential of concrete. J. Clean. Prod. 2017, 166, 485-502. [CrossRef]

21. Göswein, V.; Gonçalves, A.; Silvestre, J.D.; Freire, F.; Habert, G.; Kurda, R. Transportation matters-Does it? GIS-based comparative environmental assessment of concrete mixes with cement, fly ash, natural and recycled aggregates. Resour. Conserv. Recycl. 2018, 137, 1-10. [CrossRef]

22. Marinković, S.; Habert, G.; Ignjatović, I.; Dragaš, J.; Tošić, N.; Brumaud, C. Life cycle analysis of fly ash concrete with recycled concrete aggregate. In Proceedings of the Sustainable Built Environment (SBE) Regional Conference, Hamburg, Germany, 8-11 March 2016; pp. 390-396.

23. Marinković, S.; Dragaš, J.; Ignjatović, I.; Tošić, N. Environmental assessment of green concretes for structural use. J. Clean. Prod. 2017, 154, 633-649. [CrossRef]

24. Kurda, R.; Silvestre, J.D.; de Brito, J.; Ahmed, H. Optimizing recycled concrete containing high volume of fly ash in terms of the embodied energy and chloride ion resistance. J. Clean. Prod. 2018, 194, 735-750. [CrossRef]

25. Rodrigues, P.; Silvestre, J.D.; Flores-Colen, I.; Viegas, C.A.; de Brito, J.; Kurad, R.; Demertzi, M. Methodology for the assessment of the ecotoxicological potential of construction materials. Materials 2017, 10, 649. [CrossRef] [PubMed]

26. Braga, A.; Silvestre, J.; de Brito, J. Compared environmental and economic impact of the life cycle of concrete with natural and recycled coarse aggregates. J. Clean. Prod. 2017, 162, 529-543. [CrossRef]

27. Kurda, R.; Silvestre, J.D.; de Brito, J. Toxicity and environmental and economic performance of fly ash and recycled concrete aggregates use in concrete: A review. Heliyon 2018, 4, e00611. [CrossRef] [PubMed]

28. Kurda, R.; de Brito, J.; Silvestre, J.D. Influence of recycled aggregates and high contents of fly ash on concrete fresh properties. Cem. Concr. Compos. 2017, 84, 198-213. [CrossRef]

29. Kurda, R.; de Brito, J.; Silvestre, J.D. Indirect evaluation of the compressive strength of recycled aggregate concrete with high fly ash ratios. Mag. Concr. Res. 2018, 70, 204-216. [CrossRef]

30. EN 12390-3:2009—Compressive Strength of Test Specimens. Testing Hardened Concrete; Comité Européen de Normalisation (CEN): Brussels, Belgium, 2009.

31. EN 12390-6:2009-Tensile Splitting Strength of Test Specimens. Testing Hardened Concrete; Comité Européen de Normalisation (CEN): Brussels, Belgium, 2009.

32. LNEC E 397:1993-Hardened Concrete: Determination of the Modulus of Elasticity in Compression; LNEC: Lisbon, Portugal, 1993.

33. DELLA, TM (International Information Services for Truck Transportation). Transportation Prices Europe-Europe. Available online: http:/ / www.della.eu/price/local/ (accessed on 22 December 2016).

34. Teixeira, E.R.; Mateus, R.; Camões, A.F.; Bragança, L.; Branco, F.G. Comparative environmental life-cycle analysis of concretes using biomass and coal fly ashes as partial cement replacement material. J. Clean. Prod. 2016, 112, 2221-2230. [CrossRef]

35. Orçamentos. Price of Ready-Mix Concrete, Pump Rental and Price of Fresh Concrete/m3. Portugal. Available online: http:/ / orcamentos.eu/precos-de-betao-pronto/ (accessed on 17 September 2017). 
36. Kurda, R.; de Brito, J.; Silvestre, J. Combined influence of recycled concrete aggregates and high contents of fly ash on concrete properties (Review). Constr. Build. Mater. 2017, 157, 554-572. [CrossRef]

37. Zachar, J.; Naik, T. More Sustainable and Economical Concrete Using Fly Ash, Used Foundry Sand, and Other Residuals; Università Politecnica delle Marche: Ancona, Italy, 2010.

38. Camões, A.; Aguiar, B.; Jalali, S. Durability of low cost high performance fly ash concrete. In Proceedings of the International Ash Utilization Symposium, Lexington, KY, USA, 19-22 October 2003.

39. EN-1992-1-1:2008-Eurocode 2-Design of Concrete Structures. Part 1-1: General Rules and Rules for Buildings; Comité Européen de Normalisation (CEN): Brussels, Belgium, 2008.

(C) 2018 by the authors. Licensee MDPI, Basel, Switzerland. This article is an open access article distributed under the terms and conditions of the Creative Commons Attribution (CC BY) license (http:/ / creativecommons.org/licenses/by/4.0/). 